\title{
Comparison of surgical outcomes between robotic \& laparoscopic single-site myomectomies
}

\author{
Seyeon Won, Nara Lee, Miseon Kim, Mi Kyoung Kim, Mi-La Kim, Yong Wook Jung, Bo Seong Yun, Seok Ju Seong \\ Department of Obstetrics and Gynecology, CHA Gangnam Medical Center, CHA University School of Medicine, Seoul, Korea
}

Objective: To compare surgical outcomes of robotic single-site myomectomy (RSSM) and laparoscopic single-site myomectomy (LSSM).

Methods: The medical records of 105 consecutive women who had undergone RSSM and 183 consecutive women on whom LSSM had been performed were retrospectively reviewed. The clinical characteristics and surgical outcomes between these groups were compared.

Results: Age at the time of surgery was younger among RSSM women than for LSSM patients ( $36.7 \pm 6.3$ vs. $38.7 \pm 6.7$ years, $P=0.010)$. In the RSSM group, whereas there were more unmarried ( $48.6 \%$ vs. $34.4 \%, P=0.018$ ) and nulliparous (73.3\% vs. 59.6\%, $P=0.019)$ women, there were fewer women who had undergone previous abdominal surgery ( $18.1 \%$ vs. $32.8 \%, P=0.007)$ and peritoneal adhesion (7.6\% vs. $23.0 \%, P=0.001)$. Total operation time was longer in the RSSM group than in the LSSM group (145.8 \pm 53.7 vs. $117.5 \pm 44.8$ minutes, $P<0.001)$. Estimated blood loss $(210.1 \pm 162.2 \mathrm{vs.} 161.4 \pm 158.7 \mathrm{~mL}$, $P=0.013)$ was much higher in the RSSM group than in the LSSM group. Hemoglobin decrement $(1.4 \pm 1.1 \mathrm{vs} .1 .6 \pm 1.1 \mathrm{~g} / \mathrm{dL}$, $P=0.120)$ and blood transfusion performance (1.0\% vs. $1.1 \%, P=0.910)$ were similar between the two groups. The duration of hospital stay $(4.7 \pm 0.9$ vs. $5.4 \pm 1.0$ days, $P<0.001)$ was shorter in the RSSM group. No one in the RSSM group had any operation-related complications. However, one ileus and one wound dehiscence were diagnosed in the LSSM group $(P=0.309)$.

Conclusion: Although the hospital stay might be shorter, RSSM showed longer operation time and higher estimated blood loss.

Key Words: Uterine myomectomy; Robotic surgical procedures; Laparoscopy

\section{INTRODUCTION}

Myomectomy is widely performed to preserve fertility in reproductive women. Myomectomy can be performed via ei- ther laparoscopy or laparotomy on an individualized basis [1]. Several studies have reported that with laparoscopic myomectomy, patients have less postoperative pain and shorter recovery time compared with open myomectomy [2-4].

- Received: April 11, 2019 • Revised: June 20, 2019 •Accepted: June 22, 2019

- Correspondening author: Seok Ju Seong

Department of Obstetrics and Gynecology, CHA Gangnam Medical Center, CHA University School of Medicine, 566 Nonhyeon-ro, Gangnam-gu, Seoul 06135, Korea

E-mail: sjseongcheil@naver.com

This is an Open Access article distributed under the terms of the Creative Commons Attribution Non-Commercial License (http://creativecommons.org/ licenses/by-nc/4.0) which permits unrestricted non-commercial use, distribution, and reproduction in any medium, provided the original work is properly cited. 
Therefore, the standing of laparoscopy has risen gradually while that of laparotomy has fallen [5]. As concern for cosmetics has grown, laparoscopic single-site myomectomy (LSSM) has been introduced. Single-site myomectomy has several advantages over conventional multiport myomectomy, such as better cosmetics in the form of a hidden umbilical scar and fewer trocar sites, which diminishes the possibility of visceral and vascular injury [6]. However, LSSM has several limitations. These limitations are a lack of triangulation, poor ergonomics, and instrument crowding [7].

Robotic system was introduced in 1999 to overcome the limitations of laparoscopic procedure [8]. Since the first robotic myomectomy was reported in 2004 [9], many studies have found it to be a feasible and safe surgical procedure [10-12]. One study concluded that there is no significant difference in surgical outcomes between robotic and laparoscopic myomectomy [13]. Further, the robotic system can allow for wrist movement, easier knot-and-tying and favorable ergonomics, which cannot be achieved in laparoscopic myomectomy, even with the single-site platform. However, there is as yet no report on the comparative surgical outcomes of robotic single-site myomectomy (RSSM) and LSSM. Therefore, in the present study, we compared the clinical characteristics and surgical outcomes for consecutive women who had undergone RSSM or LSSM.

\section{MATERIALS AND METHODS}

\section{Patients}

This study was ethically approved by the Institutional Review Board at CHA Gangnam Medical Center (GCl-19-11). The medical records of a total of 1,866 consecutive women who had undergone myomectomy between August 2015 and March 2018 were retrospectively reviewed. All of the women had single or multiple myoma uteri requiring surgical treatment. The decision on the surgical method to apply was made in the clinic after appropriate patient counseling. For this study, we collected patients' clinical information on age, body mass index (BMI), marital status, parity, previous surgical history, and myoma characteristics.

\section{Surgical procedures}

RSSM and LSSM had been performed by six gynecologic surgeons. All of the patients were operated on in the lithot- omy position under general anesthesia. In each case, a urinary foley catheter and RUMI uterine manipulator (CopperSurgical Inc., Trumbull, CT, USA) were inserted prior to the start of the operation.

\section{1) RSSM}

A vertical $2.3-2.5 \mathrm{~cm}$ incision was made in the umbilicus. The da Vinci ${ }^{\circledR}$ single-site ${ }^{\circledR}$ (Intuitive Surgical, Inc, Sunnyvale, CA, USA) silicon port was inserted and the abdomen was insufflated with $\mathrm{CO}_{2}$ gas. The $30^{\circ} 8.5-\mathrm{mm}$ da Vinci stereo laparoscope was connected to the robotic system camera, and the abdominal cavity was inspected. After the robotic system was vertically docked, a monopolar hook and a biopolar forceps were placed in each robotic arm, respectively. Before making the uterine incision, a diluted solution of vasopressin ( $0.25 \mathrm{U} / \mathrm{mL}$ concentration) was injected into the planned incision site as a hemostatic agent. The uterine incision was made and the myomas were enucleated. Subsequently, the monopolar hook was replaced with a wristed needle holder. Then, the uterine wall was sutured with continuous running 2-O V-LocTM (Covidien, Dublin, Ireland). After suturing, the myomas were put in an Endopouch bag (Ethicon, Johnson \& Johnson, New Brunswick, NJ, USA) and extracted through the umbilical incision without electromechanical morcellation. Lastly, the peritoneum, fascia and subcutaneous layer were approximated using 1-0 vicryl (Ethicon), and the skin was approximated using 3-0 vicryl.

\section{2) LSSM}

A vertical $2.3-2.5 \mathrm{~cm}$ incision was made in the umbilicus. A Glove port (Nelis, Seoul, Korea) was inserted and the abdomen was insufflated with $\mathrm{CO}_{2}$ gas. The $0^{\circ}$ or $30^{\circ} 5 \mathrm{~mm}$ laparoscope was inserted, and the abdominal cavity was inspected. Before making the uterine incision, a diluted solution of vasopressin $(0.25 \mathrm{U} / \mathrm{mL}$ concentration) was injected into the planned incision site as a hemostatic agent. The uterine incision was made using a monopolar or harmonic $\mathbb{R}$ hook (Ethicon, Somerville, NJ, USA), and the myomas were enucleated. The uterine wall was sutured with continuous running 1-0 or 2-O V-LocTM (Covidien). The procedures after suturing were the same as those indicated for RSSM above. 


\section{Statistical analysis}

We used the student's t-test for comparison of continuous variables and the chi-squared test for categorical variables. For determination of non-parametric statistics, Fisher's exact test was used. The analyses were performed using SPSS version 24.0 (IBM Inc., Armonk, NY, USA), and $P$-values $<0.05$ were considered statistically significant.

\section{RESULTS}

\section{Baseline characteristics}

A total of 1,866 women diagnosed as myoma uteri underwent myomectomy via laparoscopy or laparotomy between August 2015 and March 2018 at CHA Gangnam Medical Center (Fig. 1). Of them, 355 women received robotic myomectomy: 250 multi-site and 105 single-site cases. Among the RSSM cases, three were converted to the multi-site approach and one was converted to conventional laparoscopy in the course of the surgeries. Laparoscopic myomectomy was performed on 1,342 women: 1,116 multi-site and 183 single-site cases. One was converted to the multi-site approach during the surgery. There were no open conversion cases in either group.

The patients' baseline characteristics are presented in Table 1. Age at the time of surgery was younger among RSSM women than for LSSM patients (36.7 \pm 6.3 vs. 38.7 \pm 6.7 years, $P=0.010$ ). The BMI was lower in the RSSM group than in the LSSM group $\left(21.6 \pm 3.2\right.$ vs. $22.5 \pm 4.1 \mathrm{~kg} / \mathrm{m}^{2}$, $P=0.031$ ). The percentages of unmarried (48.6\% vs. 34.4\%, $P=0.018$ ) and nulliparous (73.3\% vs. 59.6\%, $P=0.019)$ women were higher in the RSSM group. Women who had undergone previous abdominal surgery (18.1\% vs. 32.8\%, $P=0.007)$ and peritoneal adhesion (7.6\% vs. 23.0\%, $P=0.001$ ) were fewer in the RSSM group. The numbers of retrieved myomas were similar between the two groups (2.6 \pm 2.3 vs. $2.5 \pm 2.3, P=0.645$ ). Also, between the RSSM and LSSM groups, the largest myomas were of similar size (6.3 \pm 1.7 and $6.1 \pm 2.1 \mathrm{~cm}, P=0.530$ ), and the estimated tumor weights were similar $(14.9 \pm 83.9$ and $117.7 \pm 108.6 \mathrm{~g}$, $P=0.819)$ as well. The location $(P=0.730)$ and type ( $P=0.649$ ) of the largest myoma also were similar between the two groups.

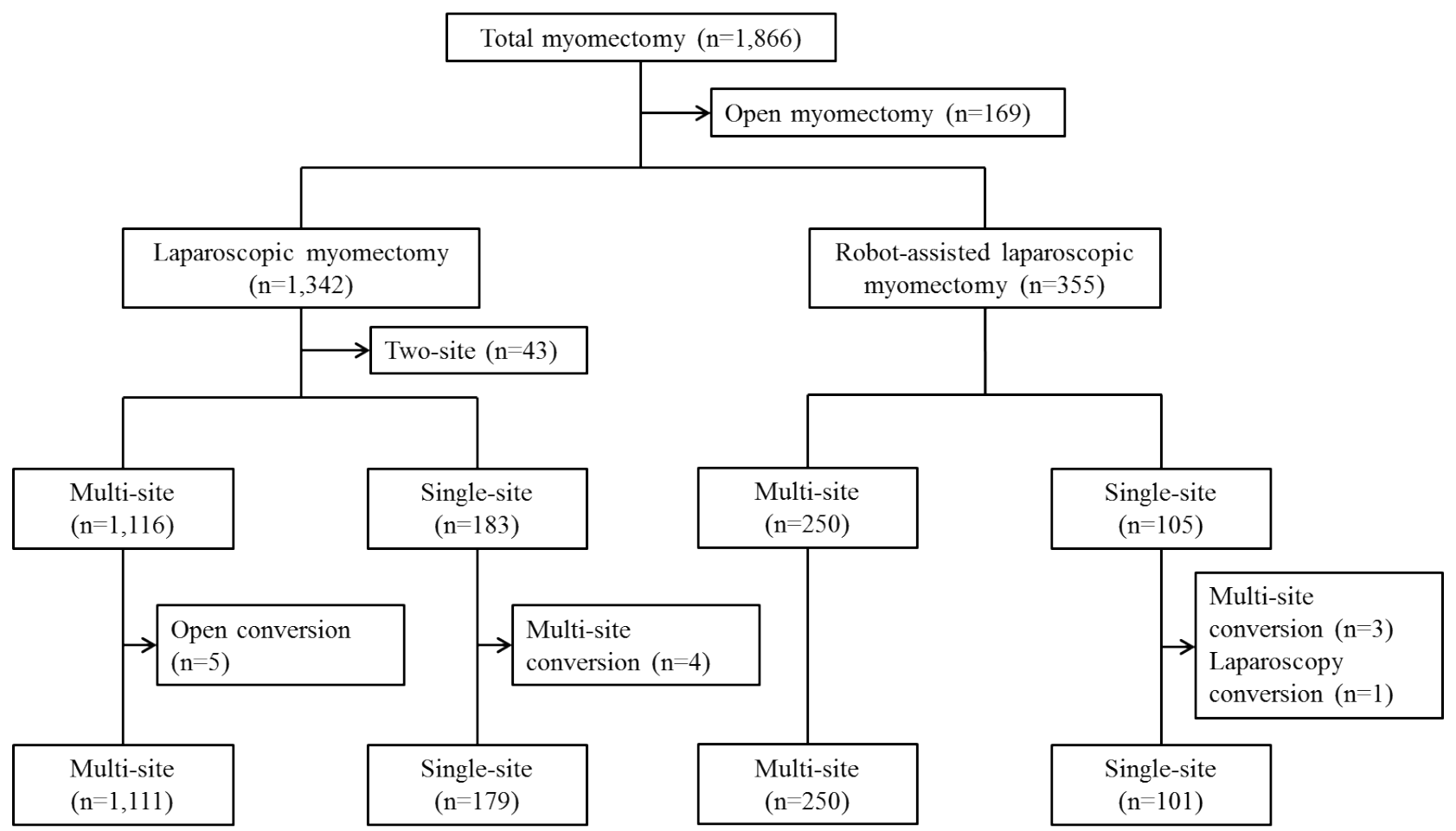

Fig. 1. Flow diagram of study population. 


\section{Perioperative outcomes}

The perioperative outcomes are summarized in Table 2. The proportions of patients who underwent concurrent surgery were not statistically different between the groups ( $P=0.677$ ). The proportions of patients who underwent multi-site conversion were not statistically different between the groups ( $P=0.708)$. There was one conversion case to laparoscopy in RSSM group.

\section{Surgical outcomes and morbidity}

Total operation time was longer in the RSSM group than in the LSSM group (145.8 \pm 53.7 vs. $117.5 \pm 44.8$ minutes, $P<0.001)$. Estimated blood loss (EBL) (210.1 $\pm 162.2 \mathrm{vs.}$ $161.4 \pm 158.7 \mathrm{~mL}, P=0.013)$ was much higher in the RSSM group than in the LSSM group. Hemoglobin decrement (1.4 \pm 1.1 vs. $1.6 \pm 1.1 \mathrm{~g} / \mathrm{dL}, P=0.120$ ) and blood transfusion performance (1.0\% vs. $1.1 \%, P=0.910$ ) were not significantly different between the two groups. On the contrary, the

Table 1. Baseline characteristics of women who underwent robotic and laparoscopic single-site myomectomies

\begin{tabular}{|c|c|c|c|}
\hline Characteristic & RSSM (n=105) & LSSM (n=183) & $P$-value \\
\hline Age (years) & $36.7 \pm 6.3$ & $38.7 \pm 6.7$ & 0.010 \\
\hline $\mathrm{BMI}\left(\mathrm{kg} / \mathrm{m}^{2}\right)$ & $21.6 \pm 3.2$ & $22.5 \pm 4.1$ & 0.031 \\
\hline Married & & & 0.018 \\
\hline No & $51(48.6)$ & $63(34.4)$ & \\
\hline Yes & $54(51.4)$ & $120(65.6)$ & \\
\hline Nullipara & & & 0.019 \\
\hline No & $28(26.7)$ & $74(40.4)$ & \\
\hline Yes & $77(73.3)$ & $109(59.6)$ & \\
\hline Previous abdominal surgery & & & 0.007 \\
\hline No & $86(81.9)$ & $123(67.2)$ & \\
\hline Yes & $19(18.1)$ & $60(32.8)$ & \\
\hline Peritoneal adhesion & & & 0.001 \\
\hline No & $97(92.4)$ & $141(77.0)$ & \\
\hline Yes & $8(7.6)$ & $42(23.0)$ & \\
\hline Total myomas & $2.6 \pm 2.3$ & $2.5 \pm 2.3$ & 0.645 \\
\hline \multicolumn{4}{|l|}{ Largest myoma } \\
\hline Size $(\mathrm{cm})$ & $6.3 \pm 1.7$ & $6.1 \pm 2.1$ & 0.530 \\
\hline Location & & & 0.730 \\
\hline Anterior & 44 (41.9) & $88(48.1)$ & \\
\hline Anterior fundus & $2(1.9)$ & $5(2.7)$ & \\
\hline Fundus & $14(13.3)$ & $24(13.1)$ & \\
\hline Posterior fundus & $2(1.9)$ & $8(4.4)$ & \\
\hline Posterior & $43(41.0)$ & $58(31.7)$ & \\
\hline Type (FIGO classification) & & & 0.649 \\
\hline Submucosal (1-2) & $4(3.8)$ & $6(3.3)$ & \\
\hline Deep intramural (3-4) & $53(50.5)$ & $78(42.6)$ & \\
\hline Intramural (5) & $24(22.9)$ & $32(17.5)$ & \\
\hline Subserosal (6) & $17(16.2)$ & $59(32.2)$ & \\
\hline Pedunculated subserosal (7) & $2(1.9)$ & $3(1.6)$ & \\
\hline Intraligamentary (8) & $5(4.8)$ & $5(2.7)$ & \\
\hline Tumor weight (g) & $114.9 \pm 83.9$ & $117.7 \pm 108.6$ & 0.819 \\
\hline
\end{tabular}

Values are presented as mean \pm standard deviation or number (\%).

RSSM, robotic single-site myomectomy; LSSM, laparoscopic single-site myomectomy; BMI, body mass index; FIGO, International Federation of Gynecology and Obstetrics. 
Table 2. Perioperative outcomes

\begin{tabular}{|c|c|c|c|}
\hline Characteristic & RSSM (n=105) & LSSM ( $n=183)$ & $P$-value \\
\hline Concurrent ovarian surgery & & & 0.677 \\
\hline No & $93(88.6)$ & $159(86.9)$ & \\
\hline Yes & $12(11.4)$ & $24(13.1)$ & \\
\hline Laparoscopy conversion & & & - \\
\hline No & $104(99.0)$ & - & \\
\hline Yes & $1(1.0)$ & - & \\
\hline Multi-site conversion & & & 0.708 \\
\hline No & $102(97.1)$ & $179(97.8)$ & \\
\hline Yes & $3(2.9)$ & $4(2.2)$ & \\
\hline
\end{tabular}

Values are presented as numbers (\%).

RSSM, Robotic single-site myomectomy; LSSM, Laparoscopic single-site myomectomy.

Table 3. Surgical outcomes and morbidity

\begin{tabular}{|c|c|c|c|}
\hline Characteristic & RSSM (n=105) & $\operatorname{LSSM}(n=183)$ & $P$-value \\
\hline \multicolumn{4}{|l|}{ Operation-related time (minutes) } \\
\hline Port placement time & $8.8 \pm 5.8$ & - & - \\
\hline Docking time & $5.1 \pm 3.6$ & - & - \\
\hline Console time & $91.5 \pm 42.6$ & - & - \\
\hline Tumor retrieval plus skin incision repair time & $41.3 \pm 23.3$ & - & - \\
\hline Total operation time & $145.8 \pm 53.7$ & $117.5 \pm 44.8$ & $<0.001$ \\
\hline Estimated blood loss (mL) & $210.1 \pm 162.2$ & $161.4 \pm 158.7$ & 0.013 \\
\hline Hemoglobin decrement (g/dL) & $1.4 \pm 1.1$ & $1.6 \pm 1.1$ & 0.120 \\
\hline Transfusion & & & 0.910 \\
\hline No & $104(99.0)$ & $181(98.9)$ & \\
\hline Yes & $1(1.0)$ & $2(1.1)$ & \\
\hline Hospital stay (days) & $4.7 \pm 0.9$ & $5.4 \pm 1.0$ & $<0.001$ \\
\hline Complications & & & 0.309 \\
\hline None & 105 (100.0) & $181(98.9)$ & \\
\hline Reoperation within 1 week & 0 & 0 & \\
\hline Ileus & 0 & $1(0.5)$ & \\
\hline Fever $>3$ days & 0 & 0 & \\
\hline Wound dehiscence & 0 & $1(0.5)$ & \\
\hline
\end{tabular}

Values are presented as mean \pm standard deviation or number (\%).

RSSM, robotic single-site myomectomy; LSSM, laparoscopic single-site myomectomy.

duration of hospital stay $(4.7 \pm 0.9$ vs. $5.4 \pm 1.0$ days, $P<0.001$ ) was significantly shorter in the RSSM group. No one in the RSSM group had any operation-related complications. However, one ileus and one wound dehiscence were diagnosed in the LSSM group $(P=0.309)$.

\section{DISCUSSION}

Several studies confirming the feasibility of RSSM have been published [9-11]. In the present study, the results on RSSM feasibility and safety were consistent with those ear- lier findings. RSSM was successfully performed regardless of the size, location, type or number of myomas, and without any complications; however, the total operation time was significantly longer than for LSSM (145.8 \pm 53.7 vs. $117.5 \pm 44.8$ minutes, $P<0.001)$. Longer operation time, which might be considered to be a critical weak point of RSSM, may be attributed to the following factors. First, in RSSM, unlike LSSM, additional docking time (5.1 \pm 3.6 minutes) is required. Secondly, the monopolar hook, the sole instrument that can be used in RSSM, has only weak traction strength for scraping of myomas, whereas in LSSM, instru- 
ments that provide strong enough traction strength, such as the tenaculum, are usable. The fact that operation time of robotic multi-site myomectomy is longer than of laparoscopic myomectomy has been reported in previous studies. Gobern et al. [14] presented a retrospective study including abdominal ( $n=169)$, laparoscopic $(n=73)$, and robotic $(n=66)$ myomectomy outcomes. Operation time for robotic surgery (140 minutes; range, 55 to 328) was longer than that for laparoscopic surgery (70 minutes; range, 17 to 218), respectively. Nezhat et al. [15] reported operation times of 234 minutes (range, 140-445) and 203 minutes (range, 95-330) for laparoscopic surgery and myomectomy, respectively, concluding that the additional operation time in the former case was attributable mainly to docking, undocking and instrument substitution.

Additionally, in the present study, EBL was higher in the RSSM group (210.1 \pm 162.2 vs. $161.4 \pm 158.7 \mathrm{~mL}, P=0.013$ ) than in the LSSM group. It has been known that wristed instrumentation and the three-dimensional vision system in robotic systems make suturing more accurate and faster [16]. These advantages may lead to decreased blood loss during operation. In fact, a meta-analysis [16] including 2,852 patients reported that $\mathrm{EBL}$ (weighted mean difference, -33.03; $P=0.02$ ) in robotic multi-site myomectomy was significantly less than that for laparoscopic myomectomy. On the other hand, our result was different. Therefore, we can conclude that blood loss is the most critical drawback of RSSM, unlike robotic multi-site myomectomy. We think that the reason is due to the lack of sufficient traction strength in RSSM, which leads to a longer enucleation phase in myomectomy and, thus too, extends the exposure of the uterus to the possibility of the incurrence of bleeding, notwithstanding the fact that suturing is more accurate and faster. In our study, hemoglobin decrement was not significantly different between the groups (1.4 $\pm 1.1 \mathrm{vs.} 1.6 \pm 1.1 \mathrm{~mL}$, $P=0.120$ ), because we checked the preoperative hemoglobin level at different times after determination of the operation schedule, and the latest time for each patient was within 1 month of surgery. Therefore, the hemoglobin decrement shown in Table 3 did not very accurately reflect the quantity of blood loss.

Another notable result of the present study is that in RSSM relative to LSSM, the women who had undergone abdominal surgery $(18.1 \%$ vs. $32.8 \%, P=0.007)$ and had peritoneal adhesion (7.6\% vs. 23.0\%, $P=0.001$ ) were fewer. This might have been a result of surgeons' tendency to choose LSSM when peritoneal adhesion is expected. If adhesion exists close to the umbilicus, more extensive movement of the instruments, including the camera, is needed. However, with a robotic system, adhesiolysis is difficult to perform for the umbilical area, given the arms' limited range of movement.

The only advantage of RSSM over LSSM in our study was shorter duration of hospital stay (4.7 \pm 0.9 vs. $5.4 \pm 1.0$, $P<0.001)$. Any factors possibly influencing recovery rate as it relates to hospital stay (e.g., postoperative pain) should be studied in the future.

This study has several limitations. First, the surgeries were conducted by six surgeons. All of them were well experienced, but the procedures' details could have differed. Second, this study was retrospective, and as such, selection bias could have been incurred in patient selection. As mentioned, surgeons tend to prefer LSSM when peritoneal adhesion is expected, which fact can be affect surgical outcomes. Third, only short-term surgical outcomes were evaluated in this study. Long-term outcomes such as those impacting on fertility and degree of cosmetic satisfaction should be assessed in the future.

To our knowledge, this is the first study to compare surgical outcomes between RSSM and LSSM. Our data shows no advantages of RSSM over LSSM other than shorter hospital stays. RSSM has the disadvantages of longer operation time and higher estimated blood loss. In future studies, long-term outcomes need to be examined.

\section{Conflict of interest}

The authors declare no conflicts of interest.

\section{References}

1. Kotani Y, Tobiume T, Fujishima R, Shigeta M, Takaya H, Nakai H, et al. Recurrence of uterine myoma after myomectomy: open myomectomy versus laparoscopic myomectomy. J Obstet Gynaecol Res 2018;44:298-302.

2. Mais V, Ajossa S, Guerriero S, Mascia M, Solla E, Melis GB. Laparoscopic versus abdominal myomectomy: a prospective, randomized trial to evaluate benefits in early outcome. Am J Obstet Gynecol 1996;174:654-8. 
3. Jin C, Hu Y, Chen XC, Zheng FY, Lin F, Zhou K, et al. Laparoscopic versus open myomectomy--a meta-analysis of randomized controlled trials. Eur J Obstet Gynecol Reprod Biol 2009;145:14-21.

4. Barakat EE, Bedaiwy MA, Zimberg S, Nutter B, Nosseir M, Falcone T. Robotic-assisted, laparoscopic, and abdominal myomectomy: a comparison of surgical outcomes. Obstet Gynecol 2011;117(2 Pt 1):256-65.

5. Lee SW, Park EK, Lee SJ, Lee KH. Comparison study of consecutive 100 cases of single port vs. multiport laparoscopic myomectomy; technical point of view. J Obstet Gynaecol 2017;37:616-21.

6. Yoshiki N, Okawa T, Kubota T. Single-incision laparoscopic myomectomy with intracorporeal suturing. Fertil Steril 2011;95:2426-8.

7. Fader AN, Escobar PF. Laparoendoscopic single-site surgery (LESS) in gynecologic oncology: technique and initial report. Gyneol Oncol 2009;114:157-61.

8. Hockstein NG, Gourin CG, Faust RA, Terris DJ. A histroy of robots: from science fiction to surgical robotics. J Robot Surg 2007;1:113-8.

9. Advincula AP, Song A, Burke W, Reynolds RK. Preliminary experience with robot-assisted laparoscopic myomectomy. J Am Assoc Gynecol Laparos 2004;11:511-8.
10. Choi EJ, Rho AM, Lee SR, Jeong K, Moon HS. Robotic singlesite myomectomy: clinical analysis of 61 consecutive cases. J Minim Invasive Gynecol 2017;24:632-9.

11. Choi SH, Hong S, Kim M, Bae HS, Kim MK, Kim ML, et al. Robotic-assisted laparoscopic myomectomy: the feasibility in single-site system. Obstet Gynecol Sci 2019;62:56-64.

12. Kim M, Kim MK, Kim ML, Jung YW, Yun BS, Seong SJ. Robotic single-site myomectomy: a single-center experience of 101 consecutive cases. Int J Med Robot 2019;15:e1959.

13. Iavazzo C, Mamais I, Gkegkes ID. Robotic assisted vs laparoscopic and/or open myomectomy: systematic review and meta-analysis of the clinical evidence. Arch Gynecol Obstet 2016;294:5-17.

14. Gobern JM, Rosemeyer CJ, Barter JF, Steren AJ. Comparison of robotic, laparoscopic, and abdominal myomectomy in a community hospital. JSLS 2013;17:116-20.

15. Nezhat C, Lavie O, Hsu S, Watson J, Barnett O, Lemyre M. Robotic-assisted laparoscopic myomectomy compared with standard laparoscopic myomectomy-a retrospective matched control study. Fertil Steril 2009;91:556-9.

16. Wang T, Tang H, Xie Z, Deng S. Robotic-assisted vs. laparoscopic and abdominal myomectomy for treatment of uterine fibroids: a meta-analysis. Minim Invasive Ther Allied Technol 2018;27:249-64. 